\title{
The elderly in the psychiatric emergency service (PES); a descriptive study
}

Yves Chaput ${ }^{1 *}$, Lucie Beaulieu², Michel Paradis ${ }^{3}$ and Edith Labonté ${ }^{4}$

\begin{abstract}
Background: The impact of an aging population on the psychiatric emergency service (PES) has not been fully ascertained. Cognitive dysfunctions aside, many DSM-IV disorders may have a lower prevalence in the elderly, who appear to be underrepresented in the PES. We therefore attempted to more precisely assess their patterns of PES use and their clinical and demographic characteristics.
\end{abstract}

Methods: Close to 30,000 visits to a general hospital PES (Montreal, Quebec, Canada) were acquired between 1990 and 2004 and pooled with over 17,000 visits acquired using the same methodology at three other services in Quebec between 2002 and 2004.

Results: The median age of PES patients increased over time. However, the proportion of yearly visits attributable to the elderly (compared to those under 65) showed no consistent increase during the observation period. The pattern of return visits (two to three, four to ten, eleven or more) did not differ from that of patients under 65, although the latter made a greater number of total return visits per patient. The elderly were more often women (62\%), widowed (28\%), came to the PES accompanied (42\%) and reported «illness » as an important stressor (29\%). About 39\% were referred for depression or anxiety. They were less violent (10\%) upon their arrival. Affective disorders predominated in the diagnostic profile, they were less co-morbid and more likely admitted than patients under 65.

Conclusion: Although no proportional increase in PES use over time was found the elderly do possess distinct characteristics potentially useful in PES resource planning so as to better serve this increasingly important segment of the general population.

\section{Background}

The median age of Canada's population has been increasing since 1966, with those aged 14 and under declining since 1996, attaining $17 \%$ of the population (their lowest level in 2006) versus $13.7 \%$ for those 65 and over $(\geq 65)$ [1]. The impact of an aging population on major service points in mental health care delivery, such as the psychiatric emergency service (PES), has yet to be fully ascertained. With the exception of cognitive disorders (CD) and minor or non-specific psychiatric diagnoses, many DSM-IV disorders appear to have a lower prevalence in the elderly [2-7]. A 'Canadian Community Health Survey' suggested a relationship between mental illness severity and the probability of seeking psychiatric help [8]. Given

\footnotetext{
* Correspondence: yveschaput@bellnet.ca

1365, Rue Normand, suite 230, Saint-Jean-sur-Richelieu J3A 1T6, Quebec, Canada

Full list of author information is available at the end of the article
}

this relationship it is possible that the elderly might less frequently visit the PES for minor psychiatric symptoms. With few exceptions [9], most studies assessing PES use by the elderly in Canada and in the United-States suggest that they are underrepresented in the overall PES population [10-13]. Furthermore, increases in PES use over time by the elderly have yet to be reported.

The elderly with severe mental illness are less likely to visit the psychiatric emergency room than their younger cohorts, making preferential use of mobile psychiatric emergency teams or case-management [13-15]. In addition, even the elderly with major depression are less likely to seek or to receive psychiatric care than those under $65(<65)$ [16-18].

In the general population the most frequent DSM-IV diagnoses (other than CDs) in the elderly are the various anxiety disorders and dysthymia (or minor depression) $[2-4,17,19]$. In the medical emergency department (ED)

\section{() Biomed Central}


anxiety disorders appear to be an important part of the diagnostic profile of the 53 million visits in the UnitedStates (1992 to 2001) for reasons of mental health and, the elderly account for an increasing proportion of these visits [20]. In contrast to their increasing importance in the ED, anxiety disorders contribute little to the typical PES diagnostic profile [10,21-23]. Preliminary evidence however does suggests that the elderly may possess a PES diagnostic profile different from that of patients $<65$, one weighted towards cognitive and/or mood disorders [11,24-28], while that of those $<65$ is primarily characterized by chronic psychosis, personality and substance abuse disorders [10,21-23]. In addition, factors other than diagnosis may help differentiate the elderly PES user from those $<65$. Gender differences (a higher proportion of women), fewer self referrals, a higher hospitalization rate following the visit and the frequent presence of a contributing medical condition, have all been reported [11-13,24,28]. As such, assessing diagnostic, demographic and patterns of PES use by the elderly may contribute to better defining the role and structure of future geropsychiatric emergency health care delivery.

This study had several objectives. Our primary aim was the longitudinal assessment of yearly PES use by the elderly, using a greater than 14-year observation period during which the surrounding PES population was rapidly aging. Second, to assess the patterns of PES use by the elderly, such as multiple visits, over this same time period. Third, it was to add to the preliminary but growing body of clinical and demographic data concerning PES visits made by the elderly. The latter was done using a prospectively acquired database of visits to four PES sites in the province of Quebec, Canada, where each individual visit could contain up to 70 variables.

\section{Methods}

Data collection was as previously described [10,29]. Clinical and demographic data were obtained from all patients 18 years of age and older visiting a major downtown Montreal university teaching hospital PES (the main site) from June 15, 1985, to December 31, 2000. Each PES in metropolitan Montreal is assigned a geographic catchment area and citizens within it are obliged to seek acute psychiatric care at that service only. Approximately 4.8\% of all patients who underwent triage in the ED were referred for a psychiatric assessment.

The database began June 15, 1985 as an 'in-house' register kept by the nursing staff. By 1990 it contained eight variables (name, sex, age, catchment area, referral source, date and time of entry to, and departure from the PES, and patient disposition). For research purposes, in July 1996 the database had expanded to include a maximum of 70 variables per visit and was transformed into electronic format, including all data prior to this date. The main table contained administrative variables (chart number, name, sex, and so forth). Linked tables contained variables pertinent to the consultation process, such as date and time of arrival, reasons for the referral, disposition, and so forth. Data entry was performed by designated members of the nursing staff and by the principal investigator. If neither was present, charts were held in the PES until they could be reviewed for all pertinent information. This database was used at the main site from July 1996 to December 2000, after which only the original 8 variables of the register were acquired until September 2002.

The expanded database described above was once again used for a two-year period beginning September 2002, at the main site and at three functionally dissimilar services. Two of these latter services were in cities other than Montreal. One was in Quebec City (300 km east of Montreal, approximately 500,000 citizens) and the other in SaintJean-sur-Richelieu (40 km south of Montreal, metropolitan population of approximately 90,000). This latter site differed from the other three by not having an observation area with short-term beds [30]. The second Montreal PES was in a psychiatric institute and did not have an ED (or prior medical triage). As such, it largely functioned as a "walk-in clinic". All variables in the database were listed in a paper format, which was used as the primary triage instrument for all patients visiting the four services during the two-year period. The completed forms were forwarded to the principal investigator on a weekly basis for data entry.

Many strategies were used in order to minimize diagnostic uncertainty in both data collection efforts. First, as over $60 \%$ of PES visits have been shown to occur within the daytime hours [10] only services that were covered on weekdays by experienced, regular daytime psychiatric staff with over 5 years experience in the PES setting were included. None of the four sites provided midnight to 7 am assessments. Patients referred to the PES during this time period were kept in the psychiatric observation area for assessment in the morning. As such, during weekdays, well over 70 to $80 \%$ of patients were assessed by the regular PES staff. Most staff obtained their medical and specialty training at one of the four medical faculties in the province and thus shared a common set of methodologi$\mathrm{cal} /$ ethical/cultural standards. Second, diagnoses, made using DSM-IV guidelines during non-structured clinical interviews, were obtained either directly from staff after the patient assessment or from the patient's chart. Third, diagnoses were grouped into broad categories, which included 'none', 'adjustment', 'anxiety', 'personality', 'affective', 'schizophrenia', 'psychosis not otherwise specified', 'substance abuse' and 'organic mental disorders'. Fourth, in patients with two or more visits a "most probable" primary diagnosis was attributed, which was the diagnosis most frequently given. The second most frequently 
attributed diagnosis was retained as co-morbidity. Fifth, as previously reported [10], from 65 to $80 \%$ of frequent users at all sites were at one point in time under multidisciplinary outpatient care and as such any diagnostic uncertainty could be clarified with the treating team.

\section{Primary data analysis}

Only visits where age could be accurately determined (98\% of all visits) were used. Data was analyzed using Systat (Version 13). Three datasets were extracted from the main database. Longitudinal, frequency of PES use and temporal variables were analyzed using data collected between January 1990 and August 2004 at the main site ("A" dataset, 15,579 patients, 29,985 visits). Statistical differences between numerical means (ages, number of visits or time of presentation) for patients 65 and over (versus patients under 65) were determined using $t$-test for non-paired values.

Some clinical variables (diagnoses, pertinence of the visit) were acquired at the main site from July 1996 to December 2000 and similarly acquired at all sites from September 2002 to August 2004. These data were pooled and comprised dataset "B" (21,732 patients, 36,776 visits). Lastly, some socio demographic and clinical variables were only acquired during the multicenter (September 2002 to August 2004) part of this study (dataset "C", 14,850 patients, 22,881 visits, combining all 4 sites).

Most variables of the $B$ and $C$ datasets were of the nominal type (binary or with multiple categories). Preliminary analyses consisted of constructing contingency tables where the binary independent grouping variable $(\geq 65,<65)$ was tabulated with a response variable (presence or absence of violence...). If the $p$-values for the Pearson chi-square and the likelihood ratio chi-square were $<0.05$ then data were re tabulated using a goodness of fit model to determine if the response variable's profile differed significantly from the independent variable using the distribution ratios of the $\geq 65$ group as the expected frequencies. If the Pearson and likelihood ratio chisquare $p$-values remained $<0.05$ then data were tabulated using multi-way standardized tables with gender as a strata variable. Only data where all three procedures were significant are presented in the results section as "Pchi2 \& LRc2, $p<0.05$ ". Determining the strength (or direction) of an association between the response and independent variable was not the primary goal of this study. However, when pertinent, logistic regression with the resulting Odds Ratios (uncorrected for gender) and their $95 \%$ confidence intervals was used in order to assess it.

This study was approved by the institutional review board (IRB) scientific subcommittees at all sites and was exempted from full review other than at the second
Montreal site, where full IRB approval was required and obtained.

\section{Results}

Longitudinal data, temporal patterns and frequency of PES use at the main site.

Patients $\geq 65$ represented $8.7 \%(\mathrm{~N}=1349)$ of all patients and $7.2 \%$ of all visits $(\mathrm{N}=2171)$ of the A dataset at our main site. Averaging the Montreal city 1996 and 2001 census the elderly accounted for approximately $14.6 \%$ of the city population [1,31]. Of the 1349 patients $\geq 65,36 \%, 27 \%, 20 \%$ and $16 \%$ were aged between 65 and 69, 70 and 74, 75 and 79 and 80 and over, respectively. Overall, $62 \%$ were women $(\mathrm{N}=839)$ versus $44 \%$ ( $N=6315$ of 14,230 patients $)$ of those $<65$. During the 14.5-year data acquisition period there was a yearly increase in the mean (from $36.6 \pm 18$ to $40.8 \pm$ 14) and median (from 35 to 39) age of individual patients (each counted only once/year) visiting this PES. Significant differences were found ( $\mathrm{p}<0.01, t$-test for unpaired values) when comparing the average mean age for the first 4 years $(38.7 \pm 16.7)$ to that of the last 4 years of the observation period $(41.1 \pm 14.3)$. On a yearly basis the mean age of women was always slightly higher than that of men and, in all but the final year (2004) this difference was statistically significant ( $\mathrm{p}$ $0.01, t$-test for unpaired values). The proportion of the total number of yearly visits attributable to patients $\geq 65$ (compared to those $<65$ ) showed no consistent increase over time (table 1). When patients/year was analyzed there was a significant reduction in the average proportion of patients $\geq 65$ during the last 4 years compared to the first 4 years $(7.7 \pm .44 \%$ versus $9.6 \pm .9 \%, \mathrm{p}<$ $0.05, t$-test for unpaired values) of this study.

The overwhelming majority of all visits (75\% for patients $\geq 65$ and $65 \%$ for those $<65$ ) were between 7:00 and 17:59. Few in either group visited the PES between midnight and 06:59 (5\% of visits for patients $\geq$ 65 and $10 \%$ of those $<65)$. The average number of daily visits from Monday to Friday was $16.3 \% \pm 0.5$ for those $\geq 65$ and $15.3 \% \pm 0.8$ for those $<65$ (NS, $\mathrm{p}=0.055, t$ test for unpaired values). The average number of visits/ month was equal $(8.3 \%)$ for both groups $( \pm 0.9$, range 7.2 to 10.1 for patients $\geq 65, \pm 0.5$, range 7.8 to 9.1 for those $<65)$. No seasonal differences were observed between groups ( $t$-test for unpaired values).

Frequency of use was examined by dividing patients into groups making one $(\mathrm{N}=11,058)$, two or three $(\mathrm{N}=$ $2669)$, four to ten $(\mathrm{N}=848)$ or eleven or more visits $(\mathrm{N}$ = 155). These anchor points have been shown to result in distinct diagnostic subgroups of PES users [10,23,29]. Age at the first visit from 1990 onward determined if patients were attributed $\mathrm{a} \geq 65$ or $\mathrm{a}<65$ tag. Within the 
Table 1 Proportion (in \%) of the total yearly number of visits (V) attributable to patients $\geq 65$

\begin{tabular}{|c|c|c|c|c|c|c|c|c|c|c|c|c|c|c|c|}
\hline Year & 90 & 91 & 92 & 93 & 94 & 95 & 96 & 97 & 98 & 99 & 00 & 01 & 02 & 03 & 04 \\
\hline$\geq 65$ & 7.2 & 7.3 & 6.7 & 8.8 & 7.9 & 8.1 & 6.5 & 8.2 & 7.9 & 6.6 & 6.2 & 7.0 & 7.4 & 6.4 & 7.1 \\
\hline$<65$ & 92.8 & 92.7 & 93.3 & 91.2 & 92.1 & 91.9 & 93.5 & 91.8 & 92.1 & 93.4 & 93.8 & 93 & 92.6 & 93.6 & 92.9 \\
\hline
\end{tabular}

$\geq 65$ group single visits were made by $79.3 \%(\mathrm{~N}=940)$, two to three visits by $16.5 \%(\mathrm{~N}=196)$, four to ten visits by $3.9 \%(\mathrm{~N}=46)$ and eleven or more by $0.3 \%(\mathrm{~N}=3)$ patients. The corresponding numbers in patients $<65$ were $74.7 \%(\mathrm{~N}=10,118), 18.3 \%(\mathrm{~N}=2473), 5.9 \%(\mathrm{~N}=$ $802)$ and $1.1 \%(\mathrm{~N}=152)$, respectively. Overall, the frequent user profile was not significantly different between the two groups. However, the average number of visits/ patient for all patients making over three visits, regardless of the total, was $5.5( \pm 2.2)$ versus $7.7( \pm 6.9)$ for those $\geq 65$ and those $<65$, respectively $(\mathrm{p}<0.05, t$-test for unpaired values).

\section{Socio demographic variables}

Marital $(\mathrm{N}=1332, \mathrm{~N}=15,356$, visits for patients $\geq 65$ and $<65$, respectively), employment $(\mathrm{N}=1315, \mathrm{~N}=$ 16,632 visits for patients $\geq 65$ and $<65$, respectively) and residential profiles $(\mathrm{N}=1392, \mathrm{~N}=17,978$ visits for patients $\geq 65$ and $<65$, respectively) were derived from the $B$ dataset. The educational profile $(\mathrm{N}=720$ and $\mathrm{N}=$ 9,838 visits for patients $\geq 65$ and $<65$, respectively) was derived from the $\mathrm{C}$ dataset. All four profiles showed significant (Pchi2 \& LRc2, $p<0.001$ ) between group differences. Those $\geq 65$ were more frequently widowed $(28 \%$ versus $1 \%$ ), less frequently single (24\% versus $55 \%$ ) than patients < 65 whereas the percent 'married/living together' (29 versus 23\%) or 'separated/divorced' (20\% each) were comparable. The proportion of patients $\geq 65$ who were 'retired versus actively employed ' $(82 \%$ versus $1.7 \%)$ differed markedly and expectedly from that of those $<65$ (2.5\% versus $32 \%$,). Few patients $\geq 65$ were receiving welfare, an income supplement program or any kind of employment insurance (11 versus $49 \%$ for those $<65$ ). Those $\geq 65$ were also more likely to live in a residence or another kind of non-family supervised housing (37.5\% versus $14 \%)$, to be homeowners $(14.5 \%$ versus $8.5 \%$ ), less likely to be renting (apartment/room, $42.9 \%$ versus $64.8 \%$ ) or living with family (1.5\% versus $5.4 \%)$. Those $\geq 65$ were less well educated, most having only a grade school (54\% versus $11 \%$ ) or high school (34\% versus $56 \%$ ) education, with fewer attaining either the college or university level (11\% versus $33 \%)$.

\section{Arrival to the PES and prior clinical history}

Type of arrival to the PES was taken from the $\mathrm{C}$ dataset $(\mathrm{N}=1420, \mathrm{~N}=18731$ visits for patients $\geq 65$ and $<65$, respectively) and showed significant between group differences (Pchi2 \& LRc2, $p<0.001$ ). Patients $\geq 65$ less frequently presented alone (14\% versus $31 \%)$, being more often accompanied by a significant other or a caretaker (42\% versus $30 \%$ ). Police (5.7 versus $9.7 \%$ ), ambulance (28 versus 21\%), transfers from surrounding PESs (6.7 versus 6\%) or "any other" (3 versus $2.6 \%$ ) type of arrival was similar in those $\geq 65$ and $<65$. Voluntary (versus involuntary, regardless of the type of arrival) arrival did not differentiate one group from the other ( 81 and $83 \%$ of visits were voluntary for patients $\geq 65$ and $<65$, respectively).

Violence upon arrival was assessed from the B dataset $(\mathrm{N}=1491, \mathrm{~N}=19,379$ visits, patients $\geq 65$ and $<65$, respectively) using logistic regression. Visits from patients $\geq 65$ were less frequently tagged as violent (10 versus $20 \%$, OR $0.55, p<0.001$, CI 0.47-0.64). No difference was found as to the nature of the aggressive acts (verbal, physical or both) but staff reactions to the acts did differ between the two groups $(\mathrm{N}=67, \mathrm{~N}=989$ visits, patients $\geq 65$ and < 65 , respectively, Pchi2 \& LRc2, $p<0.05)$. A verbal approach to contain the aggression was more often used with the elderly (66\% versus $48 \%$ ), rather than isolation (18\% versus $23 \%)$, restraints alone ( $1 \%$ versus $7 \%$ ) or the combination of restraints and isolation (15 versus $21 \%$ ).

Both groups had a similar rate (about 40\%) of at least one prior psychiatric hospitalization. Using logistic regression a history of substance abuse was less frequently found (OR 0.34, $p<0.001$, CI $0.31-0.38)$ in patients $\geq 65(27 \%$, 457 of 1679 visits) than in those < 65 (57\%, 13,937 of 24,371 visits). When present, substance abuse was primarily observed in men (versus women) in both groups (approximately 63\% in men, 37\% in women). The pattern of abuse was obtained for 333 (of the 457) visits and in 9206 (of the 13,937) visits of patients $\geq 65$ and $<65$, respectively. It was found to be much narrower in patients $\geq 65$ (93\% alcohol, 1\% cannabis, 4\% multiple substance, $1 \%$ benzodiazepines) versus (42\% alcohol, $18 \%$ cannabis, $5 \%$ cocaine and $32 \%$ multiple substances, $3 \%$ other) in those $<65$ (Pchi2 \& LRc2, $p<0.001$ ).

Current psychiatric medication ( $\mathrm{C}$ dataset) was observed in 1135 of 1297 visits of patients $\geq 65$ (88\%) and in 12,420 of 17,353 visits (71\%) of those $<65$ (OR $2.6, p<0.001$, CI 2.2-3.0). The primary drug differentiating the former from those $<65$ was the benzodiazepine class (39\% versus $28 \%$, OR $1.3, p<0.001$, CI 1.15-1.43).

\section{Visit characteristics}

The over 30 reasons for a psychiatric referral were collapsed into 10 logical groupings (B dataset) for purposes 
of analysis. Compared to patients $<65$ (27,286 visits), the profile for those $\geq 65$ (2,132 visits) differed significantly (Pchi2 \& LRc2, $p<0.001$ ). It was marked by fewer referrals for "suicidal ideation" ( $8 \%$ versus $19 \%$ ) or "suicide attempt" ( $2 \%$ versus $8 \%$ ) and a greater number of referrals for "depression" (28 versus 20\%). Few patients $\geq 65$ were specifically referred for CDs (1.3\%). Categories relating to "psychosis" (approximately 19\% each), "hypomania/mania" (5 versus 3\%), "anxiety" (11 versus 9\%), "behavioral dyscontrol" (approximately 10\% each), "other" (7 versus 6\%) and "no specific reason" (7\% each) were similar in both groups. About $65 \%$ of patients in both groups reported the presence of psychosocial stressors prior to their visit and these are illustrated in Figure 1. Diagnostic differences (for both visit and patient data) are presented in Figure 2. In addition, $30 \%$ for those $\geq 65$ were co-morbid with a psychiatric disorder versus $42 \%$ of patients $<65$. Figure 3 illustrates the most frequent psychiatric co-morbid diagnoses in both groups. Figure 4 illustrates visit outcomes.

The relationship between diagnosis and frequency of PES use is illustrated in table 2. In both groups, the proportion of patients with chronic psychosis increased and, those without a clear diagnosis, adjustment disorders or psychosis not otherwise specified, decreased with increasing frequency of use. Also, substance abuse contributed less to the overall profile of those with 11 or more visits. Notable between group differences were affective and personality disorders (increasing and decreasing, respectively, as frequency of use increased in those $\geq 65$ ). The proportion with anxiety disorders was relatively independent of PES use in patients $\geq 65$ but decreased with increasing visit frequency in patients

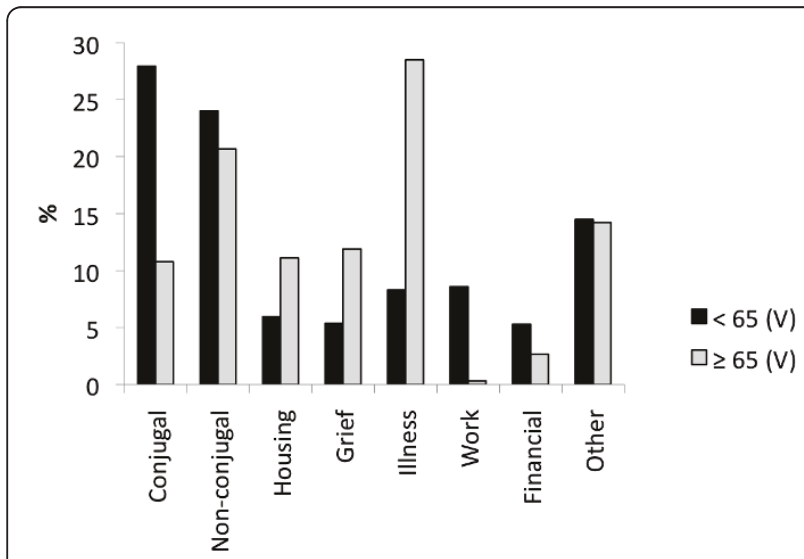

Figure 1 Life-events associated with a PES visit ( $C$ dataset, $\mathbf{N}=$ 13,214 visits, patients $<65, N=899$ visits, patients $\geq 65$ ). The profiles differed significantly (Pchi2 \& LRc2, $p<0.001$ ). Conjugal life events included those in married, common law or any long term intimate relationship. Non-conjugal included any other type of relationship. Illness was in "self" or in a "significant other".

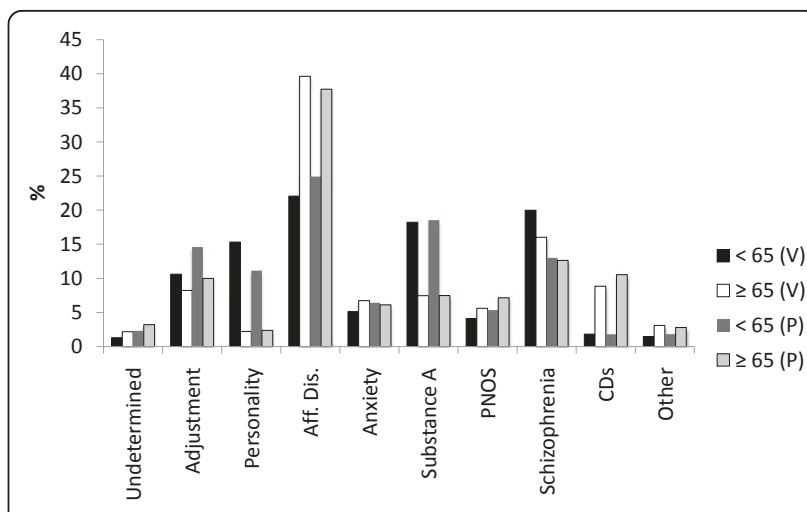

Figure 2 Primary diagnostic profile for those $\geq 65$ (visits = 2215 , patients $=910$ ) compared to those $<65$ (visits $=29,704$, patients $=7600)$, from the $B$ dataset. $(V)=$ visits, $(P)=$ patients. The profiles differed significantly, Pchi2 \& LRc2, $p<0.001$. Aff.Dis $=$ unipolar, bipolar disorders and dysthymia, Substance $A=$ alcohol and/or drugs, PNOS = psychosis not otherwise specified, $C D=$ cognitive disorders, Other = impulse control, eating, sexual and primary sleep disorders.

$<65$. For each frequency anchor point patients $<65$ were significantly more co-morbid than those $\geq 65$ (ORs ranging from 1.6 for single visits to 1.5 for 11 or more visits, $\mathrm{P}$ values $<0.01)$.

Finally, as previously reported [30] staff were asked to qualitatively grade 1,604 visits from patients $\geq 65$ and 21,607 visits of those $<65$ (B dataset) for both pertinence and urgency. About 57\% ( $\geq 65)$ and $52 \%(<65)$ of visits were judged pertinent and urgent, $28 \%$ in both groups were judged pertinent but not urgent, $11 \%(\geq$ $65)$ and $15 \%(<65)$ neither pertinent nor urgent. An assessment was not made in $5 \%$ in both groups. These profiles were not significantly different.

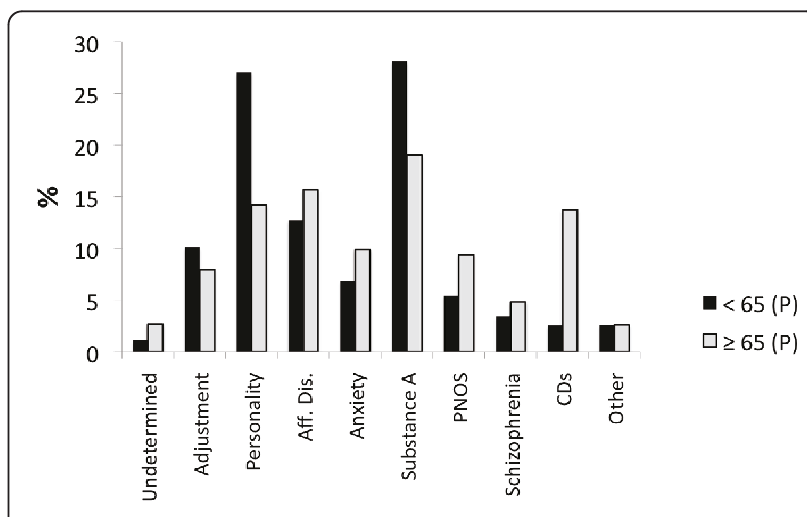

Figure 3 The co-morbid diagnostic profile of patients $\geq 65$ (N $=464)$ compared to that of patients $<65(\mathrm{~N}=8006)$, from the B dataset. The profiles differed significantly, P $<0.001$, Pchi2 \& LRc2, $p<0.001$. For legend, see figure 2 . 


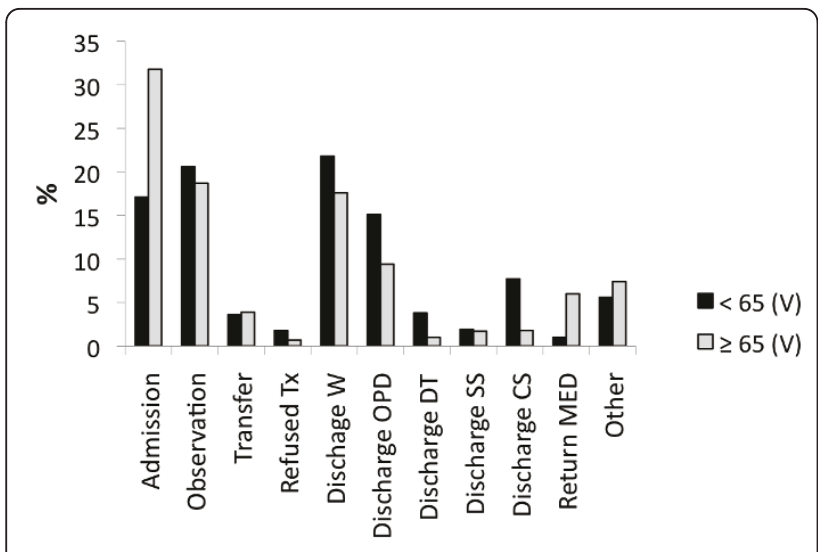

Figure 4 Outcome profile of patients $\geq 65(\mathrm{~N}=3030)$ compared to that of patients $<65(\mathrm{~N}=39,455)$, from the combined A and B datasets. The profiles differed significantly, Pchi2 \& LRc2, $p<0.001$. Admission $=$ to a psychiatric ward, Observation $=$ in the PES, Transfer $=$ to another PES, Refused Tx $=$ Left against medical advice, Discharge $(W=$ without recommendations, OPD $=$ to outpatient follow-up, DT $=$ detoxification center, $\mathrm{SS}=$ social services, $C S=$ crisis service), Return $\mathrm{MED}=$ patient was returned to the medical emergency service.

\section{Discussion}

The median age of all citizens in the province of Quebec (Canada), of which Montreal metropolitan represents about half of the total population, increased by slightly more than 4 years between 1991 and 2001 and by 6 years between 1991 and 2006 [1,32]. This increase was mirrored by a 4-year increase in the median age of patients visiting our main PES site from January 1990 to August 2004.

In contrast to the reported increase in ED use for reasons of mental health by the elderly in the United-Sates from 1985 to 2000 [20], on a yearly basis, we found no proportional increase (in individual patients or their often multiple visits) in PES use during the over 14-year time course of our study. A relatively stable yearly rate of PES use, as assessed by the actual total number of visits/year by the elderly, was also reported by Cully et al., in Houston Texas, between 1994 and 2001 [12].

Many studies assessing PES use by the elderly suggest that they are underrepresented in this service [10-13]. In the present study they accounted for $7.2 \%$ of all PES visits, about half of their proportion in the surrounding population. Whether this implies that they actually underuse the PES is unclear. Despite ongoing research, a consensus as to what constitutes a "psychiatric emergency" remains elusive [30,33]. Qualitatively, visits made by the elderly were found to be indistinguishable from those made by younger patients, as assessed by the staff's subjective rating of each visit's pertinence and urgency. Over $50 \%$ and over $80 \%$ of their visits were tagged either "urgent" or "pertinent", respectively. However, many visits were also tagged "not urgent" in both the elderly and in those $<65$. Using an "admission and/ or observation" outcome as a less subjective index one might speculate that the elderly make better use of the PES than their younger counterparts (51\% admission/ observation rate versus $38 \%$ for those $<65$ ). Indeed, a higher admission rate has been reported in several other studies [11-13,24,28]. However, many non-psychiatric reasons, such as transportation problems or a poor social support network, may mitigate admitting an elderly, but not a younger, comparably ill patient.

Rather unexpected was the high number of repeat visits made by the elderly. High frequency PES use has typically been associated with a younger cohort, one with a diagnostic profile weighted towards schizophrenia and personality disorders [22,23,29,34,35]. In contrast, the elderly frequent user more typically suffered from an affective disorder, a finding in line with several studies showing a preponderance of affective and/or cognitive disorders in the overall elderly PES (and ED) diagnostic profile $[11,12,24-28,36]$. That only $10 \%$ of the elderly had CDs in our study is most likely attributable the ED staff's direct access to admission beds in a family medicine unit of the hospital specifically designated for the

Table 2 Relationship between frequency ${ }^{1}$ of PES use and diagnosis ${ }^{2}$ (in \%)

\begin{tabular}{|c|c|c|c|c|c|c|c|c|c|c|c|c|}
\hline & & None & $A D$ & $P D$ & $M A D$ & $\mathrm{SCH}$ & $A X$ & $S A$ & $C D$ & PNOS & OTH & Visits $^{3}$ \\
\hline $1 \mathrm{~V}$ & $64-$ & 18 & 16 & 8 & 20 & 7 & 6 & 19 & 1 & 5 & 0.5 & 6314 \\
\hline $1 \mathrm{~V}$ & $65+$ & 19 & 10 & 2 & 24 & 10 & 7 & 10 & 11 & 5 & 3 & 557 \\
\hline $2-3 V$ & 64- & 9 & 11 & 10 & 21 & 14 & 5 & 21 & 2 & 4 & 2 & 4604 \\
\hline $2-3 V$ & $65+$ & 12 & 5 & 1 & 33 & 14 & 5 & 7 & 7 & 6 & 10 & 339 \\
\hline $4-10 \mathrm{~V}$ & 64- & 0 & 4 & 17 & 20 & 30 & 3 & 21 & 1 & 3 & 2 & 4994 \\
\hline $4-10 \mathrm{~V}$ & $65+$ & 0 & 2 & 4 & 53 & 18 & 6 & 6 & 4 & 2 & 6 & 428 \\
\hline $11+V$ & $64-$ & 0 & 0.5 & 25 & 15 & 45 & 1 & 12 & 1 & 1 & 0.5 & 5136 \\
\hline $11+V$ & $65+$ & 0 & 0 & 0 & 48 & 35 & 7 & 5 & 5 & 0 & 0 & 219 \\
\hline
\end{tabular}

${ }^{1}$ Single visit ( $\left.1 \mathrm{~V}\right), 2$ to 3 visits $(2-3 \mathrm{~V}), 4$ to 10 visits $(4-10 \mathrm{~V})$ and 11 or more visits $(11+\mathrm{V})$.

${ }^{2}$ None $=$ no clear diagnosis, $\mathrm{AD}=$ Adjustment disorders, $\mathrm{PD}=$ Personality disorders, MAD = Major affective disorders, $\mathrm{SCH}=\mathrm{Schizophrenia,} \mathrm{AX}=\mathrm{Anxiety}$ disorders, $\mathrm{SA}=$ Substance abuse, $\mathrm{CD}=$ Cognitive disorders, $\mathrm{PNOS}=$ Psychosis not otherwise specified, OTH = Other (paranoid psychoses, eating disorders, impulse control...).

${ }^{3}$ Data taken from the combined $A$ and $C$ datasets. Totals for each row may not equal $100 \%$, due to rounding. 
long term care and placement of CD patients. Overall, the elderly were less frequently co-morbid and the range of co-morbid diagnoses was much broader than that of younger patients, where personality and substance abuse disorders predominated. The lesser (and broader) comorbidity may have contributed to the apparent under use of the PES by the elderly. On the whole though, the relative absence of substance abuse (history of and actual diagnosis) and schizophrenia's moderate contribution to the primary diagnostic profile is largely compatible with what has been previously reported $[9,12,24,27]$. When substance abuse was present alcohol was the overwhelming drug of choice, a finding that may prove useful in the future planning of specialized psychogereatric PESs.

Recently, it has been reported that about $30 \%$ of elderly and younger involuntary referrals to a southern California PES had positive urinary screens for drugs of abuse [37] and, if the screen had included alcohol, this number would have been much greater. In the present study about $7.5 \%$ and $19 \%$ of the elderly and $18.5 \%$ and $28 \%$ of patients $<65$ had a primary or a co-morbid diagnosis of substance abuse (including alcohol), respectively. Several reasons may underlie the substantial differences between our results and those of Woo and Chen [37]. First, involuntary referrals may represent a specific subgroup that is more prone to substance misuse. In the present study, fewer than $20 \%$ of visits in both groups were involuntary. Second, our data is based upon a most probable (the most frequently attributed) primary and co-morbid diagnosis, not individual positive drug screens per visit. As such, in order to minimize diagnostic uncertainty we may have underestimated individual cases of substance misuse. For instance, in our study, a patient making 6 visits in which a personality disorder was diagnosed in 4 and substance abuse in 2 , would receive a primary diagnosis of personality disorder with co-morbid substance abuse.

Most socio demographic variables differed in predictable ways. Many elderly were widowed and almost $40 \%$ were living in some type of supervised housing. Most were retired and $87 \%$ had at best a high school (or lower) level of education. Although they were by no means the picture of social and financially stability, those $<65$ appeared more typical of the "downward drift" type patient often associated with the PES $[10,22,34,38,39]$. The latter were $75 \%$ single/divorced/separated, $49 \%$ either receiving welfare, unemployment insurance or some other type of supplementary income and $70 \%$ were either renters (rooms or apartments) or living with a family member. The life-events that brought the elderly to the PES were essentially age appropriate. They included illness (self or a significant other), grief reactions, housing and non-conjugal relational difficulties.
These were reflected in the reasons noted by the ED medical staff in requesting a psychiatric evaluation as almost $40 \%$ pertained to depression or anxiety. Overall, with the above data would have predicted that the elderly would be less violent than younger patients and this was indeed the case.

A constellation of "core findings" typical of the elderly PES patient appears to be emerging. Underrepresentation, a preponderance of affective disorders, a higher admission rate, a gender difference, fewer self-referrals and medical conditions contributing to a PES visit and more frequent benzodiazepine use were found in the present, as well as several other studies [11-13,24,28]. About $6 \%$ of the elderly were returned to the ED for further medical investigation in our study, versus less than $1 \%$ for those $<65$. To date, the few reports showing a predominance of men in the elderly visiting the PES are from services receiving a high proportion of police referrals $[40,41]$. Indeed, even in the present study, men predominated (56\%) in police referrals of elderly patients $(\mathrm{N}=50)$.

Our study suffers from several limitations. For instance, diagnostic validity and stability in a setting such as the PES. Bacca-Garcia et al., [42] using a retrospective semi administrative database found that validity and stability varied with diagnosis (best for schizophrenia, least for personality disorders) and setting (best in the inpatient, least in the outpatient, intermediate in the PES). Using purely administrative databases the PES has fared worse [43]. However, the prospective, non administrative nature of our database and the methodology used should have helped to reduce diagnostic uncertainty in a setting that has a much broader diagnostic range than the typical inpatient ward. If bias exists in our study it may be towards greater diagnostic stability and validity with increasing number of PES visits. Also, care must be taken when generalizing from what are largely regional data as they may not always accurately reflect national trends (such as the fact that the elderly with cognitive disorders were typically triaged to non-psychiatric services in this study).

\section{Conclusion}

The elderly in the PES represent a more homogeneous group than their younger counterparts. This finding could be used at both the policy and clinical level to explore avenues that might be useful in increasing their quality of care. At a policy level, prevention may be an attainable objective. Proactive community support systems targeting those with newly diagnosed physical illnesses (or in a significant other) or grief reactions might be developed, as these stressors represent close to half of all stressors associated with a PES visit. At the local, organizational level developing increasingly efficient non-coercive verbal 
pacification measures to defuse potentially explosive situations would be pertinent, as well as triage systems with a particular focus on alcohol abuse, by far the substance of abuse of choice in this population. At a clinical level the elderly frequent user's affective disorders weighted diagnostic profile and lesser co-morbidity suggests that they may be more amenable to a shift towards more appropriate outpatient resources than frequent users $<65$.

\section{List of abbreviations used}

PES: Psychiatric Emergency Service; ED: Medical Emergency Department; CD: Cognitive Disorder; Aff.Dis: Affective disorders; Substance A: Substance abuse disorder; Patients 65 years of age and over: $\geq 65$; Patients under 65 year of age: < 65; OR: Odds Ratio.

\section{Acknowledgements}

This work was partly supported by grant \# 2200-089 from 'Valorisation Recherche Québec',

\section{Author details}

1365, Rue Normand, suite 230, Saint-Jean-sur-Richelieu J3A 1T6, Quebec, Canada. ${ }^{2}$ Department of Psychiatry, Haut-Richelieu Hospital, 920 Boulevard du Séminaire Nord, Saint-Jean-sur-Richelieu J3A 1B7, Quebec, Canada. ${ }^{3}$ Department of Psychiatry, Notre-Dame Hospital, 1560 Sherbrooke street East, Montreal H2L 4M1, Quebec, Canada. ${ }^{4}$ Department of Psychiatry, EnfantJesus Hospital, 1401 18th street, Quebec G1J 1Z4, Quebec, Canada.

\section{Authors' contributions}

YC was responsible for the design of the trial, data acquisition, data analysis and data interpretation. $Y C$ was also mainly responsible for the writing of the manuscript. MP, LB and EL were site-specific principal investigators with significant input as to the design of the database and full responsibility for its implementation at their respective sites. They also had significant input as to the interpretation of the results. All authors read and approved the final manuscript.

\section{Competing interests}

The authors declare that they have no competing interests.

Received: 21 June 2010 Accepted: 15 July 2011 Published: 15 July 2011

\section{References}

1. Statistics Canada: Portrait of the canadian population in 2006, by age and sex.[http://www.statcan.gc.ca/bsolc/olc-cel/olc-cel?catno = 97-551XWE2006001\&lang=eng], Accessed at January 2008.

2. Regier DA, Rae DS, Narrow WE, Kaelber CT, Schatzberg AF: Prevalence of anxiety disorders and their comorbidity with mood and addictive disorders. Br J Psychiatry Suppl 1998, 24-28.

3. Bland RC, Newman SC, Orn H: Prevalence of psychiatric disorders in the elderly in Edmonton. Acta Psychiatr Scand Suppl 1988, 338:57-63.

4. Streiner DL, Cairney J, Veldhuizen S: The epidemiology of psychological problems in the elderly. Can J Psychiatry 2006, 51:185-191.

5. Cainey J, Coma LM, Veldhuizen S, Kurdyak P, Streiner DL: The social epidemiology of affective and anxiety disorders in later life in Canada. Can J Psychiatry 2008, 52:104-111.

6. Wade TJ, Cairney J: Age and depression in a nationally representative sample of Canadians: a preliminary look at the National Population Health Survey. Can J Public Health 1997, 88:297-302.

7. Martens PJ, Fransoo R, Burland E, Burchill C, Prior HJ, Ekuma O: Prevalence of mental illness and its impact on the use of home care and nursing homes: a population-based study of older adults in Manitoba. Can J Psychiatry 2007, 52:581-590.

8. Sareen J, Cox BJ, Afifi TO, Yu BN, Stein MB: Mental health service use in a nationally representative Canadian survey. Can J Psychiatry 2005, 50:753-761.

9. Blixen C, Lion J: Psychiatric visits to general hospital clinics by elderly persons and younger adults. Psychiatr Sen 1991, 42:171-175.
10. Chaput $Y$, Lebel MJ: Demographic and clinical profiles of patients who make multiple visits to psychiatric ermegency services. Psychiatr Serv 2007, 58:335-341.

11. Thienhaus OJ, Rowe C, Woellert P, Hillard JR: Geropsychiatric emergency services: utilization and outcome predictors. Hosp Community Psychiatry 1988, 39:1301-1305.

12. Cully JA, Molinari VA, Snow AL, Burruss J, Kotrla KJ, Kunik ME: Utilization of emergency center services by older adults with a psychiatric diagnosis. Aging Ment Health 2005, 9:172-176.

13. Woo BK: Utilization patterns of psychiatric emergency services by elderly patients. J Am Geriatr Soc 2009, 57:182-183.

14. Strathdee SA: Access to public mental health services among older adults with severe mental illness. Int I Geriatr Psychiatry 2009, 24:313-318.

15. Depp CA, Lindamer LA, Folsom DP, Gilmer T, Hough RL, Garcia P, Jeste DV: Differences in clinical features and mental health service use in bipolar disorder across the lifespan. Am J Geriatr Psychiatry 2005, 13:290-298.

16. Sewitch MJ, Cole M, McCusker J, Ciampi A, Dyachenko A: Medication use and nonadherence to psychoactive medication for mental health problems by community-living canadian seniors with depression. Can $J$ Psychiatry 2008, 53:609-620.

17. Preville M, Boyer R, Grenier S, Dube M, Voyer P, Punti R, Baril MC, Streiner DL, Cairney J, Brassard J: The Epidemiology of Psychiatric Disorders in Quebec's Older Adult Population. Can J Psychiatry 2008, 53:822-832.

18. Weinberger Ml, Mateo C, Sirey JA: Perceived barriers to mental health care and goal setting among depressed, community-dwelling older adults. Patient Prefrence and Adherence 2009, 3:145-149.

19. Preville M, Boyer R, Vasiliadis HM, Grenier S, Voyer P, Hudon C, Streiner DL, Cairney J, Brassard J: One-year incidence of psychiatric disorders in Quebec's older adult population. Can J Psychiatry 2010, 55:449-457.

20. Larkin GL, Claassen CA, Emond JA, Pelletier AJ, Camargo CA: Trends in U.S. emergency department visits for mental health conditions, 1992 to 2001. Psychiatr Serv 2005, 56:671-677.

21. Currier GW, Allen MH: Organization and function of academic psychiatric emergency services. Gen Hosp Psychiatry 2003, 25:124-129.

22. Sullivan PF, Bulik CM, Forman SD, Mezzich JE: Characteristics of repeat users of a psychiatric emergency service. Hosp Community Psychiatry 1993, 44:376-380.

23. Pasic J, Russo J, Roy-Byrne P: High utilizers of psychiatric emergency services. Psychiatric services (Washington, DC) 2005, 56:678-684.

24. Waxman HM, Carner EA, Dubin W, Klein M: Geriatric psychiatry in the emergency department: characteristics of geriatric and non-geriatric admissions. J Am Geriatr Soc 1982, 30:427-432.

25. Shulman RW, Marton P, Fisher A, Cohen C: Characteristics of psychogeriatric patient visits to a general hospital emergency room. Can J Psychiatry 1996, 41:175-180.

26. Coyne AC, Gjertsen R: Characteristics of older adults referred to a psychiatric emergency service. J Ment Health Adm 1993, 20:208-211.

27. Perez EL, Blouin J: Psychiatric emergency consultations to elderly patients in a Canadian general hospital. J Am Geriatr Soc 1986, 34:91-94.

28. Puryear $D$, Lovitt R, Miller D: Characteristics of elderly persons seen in an urban psychiatric emergency room. Psychiatr Serv 1991, 42:802-807.

29. Chaput YJ, Lebel MJ: An examination of the temporal and geographical patterns of psychiatric emergency service use by multiple visit patients as a means for their early detection. BMC Psychiatry 2007, 7:60.

30. Chaput Y, Paradis M, Beaulieu L, Labonte E: A qualitative study of a psychiatric emergency. Int J Ment Health Syst 2008, 2:9.

31. Quebec Statistics Institute(1): [Administrative regions, population by age and sex].[http://www.stat.gouv.qc.ca/donstat/societe/demographie/ dons_regnl/regional/index.htm], Accessed at, January 2008.

32. Quebec Statistics Institute: [Demographic summary of Quebec, 2008 edition].[http://www.stat.gouv.qc.ca/publications/demograp/pdf2008/ bilan2008.pdf], Accessed at January 2008.

33. Claassen CA, Hughes CW, Gilfillan S, Mclntire D, Roose A, Lumpkin M, Rush AJ: Toward a redefinition of psychiatric emergency. Health services research 2000, 35:735-754.

34. Surles RC, McGurrin MC: Increased use of psychiatric emergency services by young chronic mentally ill patients. Hosp Community Psychiatry 1987, 38:401-405. 
35. Ledoux $Y$, Minner P: Occasional and frequent repeaters in a psychiatric emergency room. Social psychiatry and psychiatric epidemiology 2006, 41:115-121.

36. Walker Z, Leek CA, D'ath PJ, Katona CLE: Psychiatric morbidit in elderly attenders at an accident and emergency department. Int I Geriatr Psychiatry 1995, 10:951-957.

37. Woo BK, Chen W: Substance misuse among older patients in psychiatric emergency service. Gen Hosp Psychiatry 2010, 32:99-101.

38. Arfken $C$, Zeman $L L$, Yeager $L$, Mischel E, Amirsadri A: Frequent visitors to psychiatric emergency services: staff attitudes and temporal patterns. J Behav Health Serv Res 2002, 29:490-496.

39. Oyewumi LK, Odejide O, Kazarian SS: Psychiatric emergency services in a Canadian city: I. Prevalence and patterns of use. Can J Psychiatry 1992, 37:91-95.

40. Niizato K, Suzuki M, Kawada F, Oshima K, Matsushita M: Analysis of psychogeriatric patients in the psychiatric emergency system. Psychogeriatrics 2003, 3:109-114.

41. Sawayama E, Takahashi M, Arai H, Nakajima K, Kano A, Sawayama T, Miyaoka H: Characteristics of elderly people using the psychiatric emergency system. Psychiatry Clin Neurosci 2009, 63:577-579.

42. Baca-Garcia E, Perez-Rodriguez MM, Basurte-Villamor I, Del Moral AL, Jimenez-Arriero MA, De Rivera JL, Saiz-Ruiz J, Oquendo MA: Diagnostic stability of psychiatric disorders in clinical practice. Br J Psychiatry 2007, 190:210-216.

43. Folsom DP, Lindamer L, Montross LP, Hawthorne W, Golshan S, Hough R, Shale J, Jeste DV: Diagnostic variability for schizophrenia and major depression in a large public mental health care system dataset. Psychiatry Res 2006, 144:167-175.

Pre-publication history

The pre-publication history for this paper can be accessed here: http://www.biomedcentral.com/1471-244X/11/111/prepub

doi:10.1186/1471-244X-11-111

Cite this article as: Chaput et al:: The elderly in the psychiatric emergency service (PES); a descriptive study. BMC Psychiatry 2011 11:111.

\section{Submit your next manuscript to BioMed Central} and take full advantage of:

- Convenient online submission

- Thorough peer review

- No space constraints or color figure charges

- Immediate publication on acceptance

- Inclusion in PubMed, CAS, Scopus and Google Scholar

- Research which is freely available for redistribution

Submit your manuscript at www.biomedcentral.com/submit
C Biomed Central 